\title{
A redução do ser humano à vida natural
}

\section{The reduction of human being to natural life}

DOI: $10.20873 /$ rpv6n2-11

\section{Kherlley Caxias Batista Barbosa}

Orcid: 0000-0003-2321-6982

Email: kherlley@uft.edu.br

\begin{abstract}
Resumo
0 artigo discute a questão da redução da existência humana à vida natural no pensamento de Hannah Arendt, analisando as práticas totalitárias de exclusão dos apátridas das esferas jurídica e política e a dominação totalitária nos campos de concentração, quando o governo totalitário operou a transformação da vida humana até atingir a aniquilação da liberdade humana e produzir um resíduo antropológico em que os seres humanos foram reduzidos à elementaridade da vida.
\end{abstract}

\section{Palavras-chave}

Arendt. Totalitarismo. Despolitização. Transformação da natureza humana. Redução da existência humana.

\section{Abstract}

The article discusses the issue of the reduction of human existence to natural life in Hannah Arendt's thought, analyzing the totalitarian practices of exclusion of stateless persons from the legal and political spheres and totalitarian domination in concentration camps, when totalitarian government operated the transformation of human life until reaching the annihilation of human freedom and producing an anthropological residue in which human beings were reduced to the elementarity of life.

\section{Keywords}

Arendt. Totalitarianism. Depoliticization. Transformation of human nature. Reduction of human existence. 


\section{Introdução ${ }^{1}$}

0 objetivo do artigo é apresentar as análises de Arendt a respeito dos processos de transformação, despolitização e redução da existência humana à elementaridade da vida natural. Concentro-me na crítica de Arendt aos governos totalitários que tinham como objetivo aniquilar a liberdade humana e reduzir existência humana à mera vida biológica, reductio ad vitam.

Arendt descortina os processos executados pelo governo totalitário para reduzir a via humana à esfera natural e eliminá-la como vida descartável. Esse processo tem seu clímax nos laboratórios de morte dos campos de concentração, mas envolve também a privação dos direitos dos apátridas no Estado-Nação, que torna os direitos humanos ineficazes e inócuos. A despolitização do cidadão na privação de seus direitos é apresentada como a ameaça inicial para a naturalização da vida.

Esse trabalho apresenta parte de uma pesquisa mais ampla que trata da relação do pensamento arendtiano com a teoria biopolítica. Como diz Mills (2018), Arendt é "um profundo ponto de referência para os teóricos" (p. 5) da biopolítica, e "a análise de Arendt do totalitarismo e racismo como uma tecnologia política - embora altamente contestada - é importante por si mesma para a compreensão da biopolítica moderna" (p. 8) Alinho-me a essa posição de Mills, e neste artigo trato da questão da redução da existência humana à vida natural a fim de delinear uma temática relevante do pensamento arendtiano presente nas reflexões de alguns teóricos da biopolítica.

\footnotetext{
${ }^{1}$ As citações das obras de Arendt referem-se, primeiramente, ao original em inglês e, em seguida, à tradução em português. Quando não aparecer a citação de ambas significa que está sendo citada apenas o original inglês com tradução nossa.
} 


\section{Governo totalitário e transformação da vida humana}

A tese principal que perpassa as reflexões de Arendt sobre o significado do fenômeno da dominação totalitária reside em definir o totalitarismo como uma forma de governo cuja essência é a dominação total do ser humano por meio da aniquilação da liberdade. ${ }^{2}$

O governo totalitário produz processos de redução da existência humana por meio da destruição da liberdade. Arendt construiu seu pensamento político com foco na possibilidade da fundação de uma forma de organização política centralizada não na negação da liberdade, mas na sua mais radical afirmação. “A razão de ser da política é a liberdade” (ARENDT, 2006, p. 145/192). Embora a teoria política de Arendt seja voltada para a política qua liberdade, suas reflexões também desvelam uma dimensão antropológica essencial para compreender a naturalização da existência humana pelo poder político, trata-se do procedimento de esvaziamento do ser humano de sua condição jurídico-política e da sua espontaneidade, reduzindo-o à condição meramente natural e biológica.

0 totalitarismo é, para Arendt, uma forma de governo inédita ${ }^{3}$, que corresponde à sociedade de massas da contemporaneidade. É uma forma de governo de dominação, que não se limita à restrição da liberdade, como fazem os governos autoritários. Na sua versão nazista, o totalitarismo executa seu projeto de eliminação da liberdade adotando mecanismos de dominação que engendram a transformação da natureza humana e produzem a fabricação de seres humanos esvaziados da condição da liberdade e reduzidos à naturalidade da vida humana.

A análise de Arendt sobre a eliminação da espontaneidade e a transformação de seres humanos mostra as consequências das experimentações de condicionamento humano realizadas no ambiente adequado para a ilimitada dominação, “os laboratórios onde mudanças na natureza humana são testadas" (ARENDT, 1973, p. 458/510).

\footnotetext{
2 "O domínio totalitário (...) visa à abolição da liberdade e até mesmo a eliminação de toda espontaneidade humana e não a simples restrição, por mais tirânica que seja, da liberdade". (ARENDT, 1973, p. 405/454). 0 que define o totalitarismo é o seu propósito de aniquilar a liberdade humana. "O totalitarismo é a negação mais radical da liberdade" (ARENDT, 1994, p. 328/347).

3 "A originalidade do totalitarismo é horrível, não porque surgiu alguma nova "ideia" no mundo, mas porque suas próprias ações constituem uma ruptura com todas as nossas tradições; elas claramente explodiram nossas categorias de pensamento político e nossos padrões de julgamento moral" (ARENDT, 1994, p. 309-10/332).
} 
Os campos de concentração são os laboratórios experimentais da dominação total, pois sendo a natureza humana o que é, esse objetivo só pode ser alcançado sob as circunstâncias extremas de um inferno feito pela mão do homem. A dominação total só é alcançada quando o ser humano, que de alguma maneira sempre é uma mistura de espontaneidade e condicionamento, foi transformado num ser completamente condicionado, cujas reações podem ser calculadas mesmo quando ele é levado à morte certa. (ARENDT, 1994, p. 240/268)

As experimentações de transformação humana no campo de concentração só foram possíveis porque os agentes executores eram guiados pela ideologia do racismo. "Esse programa inteiro de extermínio e aniquilação pôde ser deduzido das premissas do racismo" (ARENDT, 1994, p. 241-2/270) A ideologia racial adotada pelo governo totalitário nazista funcionava como a justificativa teórica da eliminação da liberdade e da redução da vida humana a sua superfluidade nos campos de concentração. A produção de uma humanidade superior e pura pressupunha a eliminação das raças consideradas inferiores e o sacrifício de indivíduos considerados nocivos, parasitas, doentes e supérfluos. (Cf. ARENDT, 1994, p. 341/360)

A ideologia racial faz crer no governo totalitário que existe, de fato, uma lei cujo movimento conduz à sobrevivência da raça superior às custas da extinção da raça inferior, gerando uma humanidade pura por ter sido purificada da contaminação da raça inferior e doente. A ideologia racial, no governo totalitário, não é teórica, mas prática, torna real o seu conteúdo ideológico ao traduzir seus postulados na ordem dos fatos e procedimentos totalitários. 0 terror totalitário materializa o projeto da ideologia racial de sacrifício dos indivíduos da raça considerada inferior. Assim a transformação do ser humano significa na prática a purificação da espécie humana por meio do sacrifício dos indivíduos impuros e inferiores. (Cf. ARENDT, 1973, p. 465/517)

A transformação do ser humano é processual, perpassa um caminho que cumpre um movimento contínuo de práticas de condicionamento e de eliminação da espontaneidade do agir. 0 resultado final do processo de transformação do ser humano verificado no campo de concentração é precedido por estágios de redução da existência humana por práticas totalitárias, presentes até mesmo em governos não-totalitários. “A desvairada fabricação em massa de cadáveres é precedida pela preparação, histórica e politicamente inteligível, de cadáveres vivos". (ARENDT, 1973, p. 447/498) 


\section{A despolitização e a redução da existência humana}

As experiências de transformação do ser humano pela dominação total realizada nos campos de transformação não surgiram ex nihilo, ao contrário, refletem a cristalização de processos históricos de privação de direitos e da dignidade do ser humano que vieram à tona no período entre as duas guerras mundiais. Arendt analisa esse contexto histórico e descreve a privação de direitos como momento antecedente à nadificação, naturalização, nudificação e eliminação da vida humana.

Para ela, uma condição para o surgimento da dominação total do ser humano é a privação de direitos e a exclusão da esfera jurídica. “A destruição dos direitos de um homem, a morte de sua pessoa jurídica, é a condição primordial para que seja inteiramente dominado". (ARENDT, 1973, p. 451/502). A perda total do status de cidadão é tematizada por Arendt na sua análise do fenômeno do surgimento em massa de minorias nacionais, apátridas e refugiados. Os povos nacionais habitantes dos novos estados, surgidos do desenho geopolítico após a Primeira Guerra Mundial, formaram minorias nacionais que não gozavam da plenitude de direitos dos povos nacionais, que eram tratados privilégio porque tinham ligação histórica e cultural com o território do Estado-Nação em que habitavam. A nacionalidade tornou-se o principal critério de definição do status político no Estado-Nação. Essa situação revelou a ineficácia das declarações de direitos humanos, uma vez que, no seu conteúdo fundamental, essas declarações pareciam garantir que todo e qualquer ser humano, pelo fato de ser simplesmente humano, poderia gozar da plenitude dos direitos independentemente do estado e do território em que se encontrasse. Mas a realidade política mostrava o idealismo dessas declarações, já que in concreto indivíduos sem o status de cidadão, encontravam-se fora da esfera de proteção de qualquer direito. "Os Direitos do Homem, supostamente inalienáveis, mostraram-se inexequíveis - mesmo nos países cujas constituições se baseavam neles - sempre que surgiam pessoas que não eram cidadãos de algum Estado soberano" (ARENDT,1973, p. 327/293). Os direitos do homem, na prática, mostraram-se inócuos para os indivíduos de nações minoritárias e desnacionalizados. Sem estado e sem nação, os indivíduos tornaram-se seres humanos sem direitos, relegados ao campo da exceção jurídica; "somente as pessoas da mesma origem nacional 
podiam gozar de toda a proteção das instituições legais, que os indivíduos de nacionalidades diferentes precisavam de alguma lei de exceção" (ARENDT, 1973, p. 275/308).

A crítica de Arendt à inaplicabilidade dos direitos humanos pelo Estado-Nação ${ }^{4}$ retrata a condição elementar de vida dos apátridas, indivíduos desnacionalizados e privados de direitos fundamentais e, por conseguinte, reduzidos a uma condição de vida despolitizada. 0 apátrida vive uma situação existencial de privação de diversas condições que qualificam a vida humana. É privado de um lugar no mundo no sentido de que lhe é negado o pertencimento a uma comunidade em que que possa agir e expressar sua opinião. A privação de pertencimento a uma comunidade política, a despolitização, tem a grave implicação de excluir o ser humano da humanidade.

Tal despolitização não significa simplesmente a privação desse ou daquele direito fundamental, mas indica algo mais profundo à medida que atinge o ponto de ser a negação até mesmo da possibilidade de ter direitos. 0 apátrida não é simplesmente o stateless, o sem-estado, mas aquele que não pode ser cidadão de nenhum estado. (Cf. ARENDT, 1973, 296/330)

Arendt indica como a desnacionalização se mostrou um eficaz dispositivo estatal de despolitização ${ }^{5}$, dando vias ao processo de exclusão total da comunidade humana organizada, relegando o apátrida à situação de interminável risco à sua vida.

A privação do pertencimento ao mundo jurídico e político, a despolitização da existência humana, implica a condução do ser humano a uma situação existencial que Arendt caracteriza como:

1) "a abstrata nudez de ser unicamente humano e nada mais" (ARENDT, 1973, p. 297/331). A nudez da existência é o resultado da perda de qualidades humanas que pressupõe

\footnotetext{
${ }^{4}$ Arendt critica as declarações dos Direitos do Homem partindo da realidade da exclusão dos apátridas e das minorias da esfera de proteção jurídica do Estado Nação. “Os Direitos do Homem, afinal, haviam sido definidos com "inalienáveis" porque se supunha serem independentes de todos os governos; mas sucedia que, no momento em que seres humanos deixavam de ter um governo próprio, não restava nenhuma autoridade para protegê-los e nenhuma instituição disposta a garanti-los". (ARENDT, 1973, p. 291-2/325)

50 exemplo mais eloquente da utilização do dispositivo da desnacionalização tendo em vista redução da vida abrindo caminho para sua eliminação é dado por Arendt quando descreve o método nazista de execução do processo que leva da privação dos direitos à privação da vida: 1) Hitler desnacionalizou os judeus, reduzindo-os a uma minoria sem direitos jurídicos na Alemanha; 2) Os judeus foram expulsos como apátridas; 3) Quando reagrupados, foram enviados para prisão ou eliminação nos campos de concentração. (Cf. ARENDT, 1973, p. 290/323)
} 
as relações do ser humano no interior de um mundo comum organizado por leis, uma comunidade;

2) uma vida meramente natural, quando os seres humanos "passam a pertencer à raça humana da mesma forma como animais pertencem a uma dada espécie de animais" (ARENDT, 1973, p. 302/335);

3) uma simples existência, quando o indivíduo padece a exclusão do espaço público e sua vida é relegada à esfera privada, vivendo na dependência da ajuda e compaixão dos outros para sobreviver. Nesse estágio da vida, o que caracteriza o ser humano é unicamente o conjunto de seus traços naturais, "misteriosamente dado pelo nascimento" (ARENDT, 1973, p. 300/334).

4) uma existência marginal; sem o pertencimento a uma comunidade política, o ser humano encontra-se fora da humanidade. "O homem pode perder todos os chamados Direitos do Homem sem perder a sua qualidade essencial de homem, sua dignidade humana. Só a perda da própria comunidade é que o expulsa da humanidade" (ARENDT, 1973, p. 297/331).

Os indivíduos que são esvaziados da condição política, e até mesmo da possibilidade de ter essa condição, são reduzidos a uma existência nua, sem as qualidades e relações que revestem a existência humana; são reduzidos a viver no âmbito da vida privada, impossibilitados de agir e falar no âmbito público; são reduzidos à elementaridade da vida, comportando-se como um espécime de sua espécie, passando a viver como um vivente, sem pode expressar seu pensamento e sem agir na comunidade política. Para Arendt nessa situação de simples existente ocorre a retirada das "mais essenciais características da vida humana", que na tradição da antropológica filosófica desde Aristóteles definem o ser humano como um animal capaz de fala e pensamento e, por isso, capaz de pertencer a uma comunidade organizada (Cf. ARENDT,1973 p. 297/330).

\section{A aniquilação da espontaneidade e a reductio ad vitam}

A dominação total do ser humano ocorreu na situação extrema de tortura e sofrimento no campo de concentração, quando os prisioneiros eram submetidos aos experimentos de transformação da natureza humana. Aí, de fato, o ser humano é reduzido a uma vida natural 
caracterizada por comportamentos condicionados que tornam a vida humana semelhante à vida das outras espécies animais.

Arendt descreve um amplo processo de perda gradativa da capacidade do ser humano de agir na realidade de forma espontânea. Nessa espontaneidade reside sua liberdade, e na subtração dela a perda do seu caráter específico de ser humano. Esvaziado de sua espontaneidade, que é a fonte das ações e reações humanas, o ser humano encontra-se totalmente reduzido à elementaridade da via humana. A singularidade do indivíduo morre, restando vivo apenas o homem na sua natural forma de vida.

Destruir a individualidade é destruir a espontaneidade, a capacidade do homem de iniciar algo novo com os seus próprios recursos, algo que não possa ser explicado à base de reação ao ambiente e aos fatos. Morta a individualidade, nada resta senão horríveis marionetes com rostos de homem, todas com o mesmo comportamento do cão de Pavlov, todas reagindo com perfeita previsibilidade mesmo quando marcham para a morte. (ARENDT, 1973, p. 455/506)

Dessa maneira, o governo totalitário da vida humana atinge seu objetivo final de realizar “a redução dos seres humanos ao mínimo denominador comum das "reações idênticas" (ARENDT, 1994, p. 268), tornando-se “um feixe der reações previsíveis" (ARENDT, 1994, p. 269), "o espécime humano reduzido às reações mais elementares" (ARENDT, 1973, p. 456/507).

O indivíduo singular, privado de seus direitos fundamentais e excluído da humanidade, abre espaço para a emergência de um espécime que realiza comportamentos repetitivos e previsíveis. A antropologia é substituída pela biologia.

Na narrativa da aniquilação da espontaneidade humana do ser humano nos campos de concentração, Arendt também descreve a redução da existência humana. A redução somente acaba quando bate no umbral da vida natural. 0 ser humano somente é humano à medida que transcende a sua condição natural. Pertencer à humanidade é mais do que pertencer à espécie humana. Com isso, as reflexões de Arendt sobre a redução da existência à mera existência levam a reconsiderar a noção de natureza humana. A natureza humana para ser humana não pode ser apenas natural. 
A experiência dos campos de concentração demonstra realmente que os seres humanos podem transformar-se em espécimes do animal humano, e que a "natureza" do homem só é "humana" na medida em que dá ao homem a possibilidade de tornar-se algo eminentemente não-natural, isto é, um homem. (ARENDT, 1973, p. 455/506)

No sentido pleno da existência, o ser humano pertence à humanidade, e não somente à espécie humana. A antropologia política considera o ser humano como ser plural e capaz de ação. A biologia trata da espécie humana e das características identificadoras e iguais de todos os membros da espécie. A antropologia política considera o ser humano como ser único e diferente enquanto pertencente à humanidade; enquanto a biologia considera o ser humano como pertencente a uma espécie animal, que se comporta de modo igual aos demais membros da espécie.

Embora Arendt adote a expressão “transformação da natureza humana”, em suas análises, a sua reflexão sobre o resíduo antropológico resultante da aniquilação da espontaneidade humana retrata menos uma transformação do que uma redução, pois nos campos de concentração os indivíduos não foram transformados em algo que ainda não eram, mas reduzidos ao que sempre já são quando ainda não entraram no mundo das relações humanas numa comunidade. 0 ser humano não é transformado no sentido de ter modificada a sua natureza, mas de se tornar unicamente 'natureza', por isso que esse processo é caracterizado como uma redução produzida pelo funil antropológico da política totalitária. 0 metódico processo de dominação totalitária reduziu o ser humano à condição de vivente humano: redução à vida. Reductio ad vitam.

\section{Conclusão}

O totalitarismo e os campos de concentração foram as experiências letais de dominação total do ser humano na contemporaneidade, com métodos e procedimentos de aniquilação da liberdade e redução da existência à vida natural. 0 totalitarismo é o modelo exemplar de uma política de dominação da vida, isto é, de uma vida colocada à mercê do poder governamental. As reflexões de Arendt sobre o governo totalitário aqui delineadas revelam-se como uma 
relevante referência para se pensar as formas de governo que adotam práticas de despolitização do cidadão no mundo atual.

O declínio dos governos totalitários infelizmente não é uma página virada do nosso passado porque a lógica interna de organização e funcionamento dessa forma de governo ainda permanece entre nós. A lógica totalitária é um campo imaginário potencial, que pode condicionar existindo no mundo em que vivemos (cf. ARENDT, 1973, p. 478-9/531), mesmo nas sociedades ditas democráticas. As reflexões de Arendt indicam como a redução da existência humana à esfera natural tem começo e onde desemboca tragicamente. 0 pensamento político de Arendt é uma tentativa de revelar uma alternativa à lógica que subjaz à forma de governo centrada no domínio, na transformação e na redução da vida dos seres humanos a estágios naturais. É uma fonte ainda hoje necessária para se pensar a política como liberdade, por um lado, e os mecanismos políticos de negação da liberdade e de redução da existência humana à vida natural, por outro.

\section{Referências}

ARENDT, H. The Origins of Totalitarianism. San Diego, New York: Harcourt Brace and Company, 1973. (Origens do Totalitarismo. São Paulo: Companhia das Letras, 1989).

ARENDT, H. Essays in Understanding (1930 - 1954). New York: Harcourt Brace and Company, 1994. (Compreender: formação, exílio e totalitarismo. Belo Horizonte: Editora UFMG, 2008).

ARENDT, H. Between Past and Future. Eight Exercises in Political Thought. New York: Penguin Books, 2006. (Entre o Passado e o Futuro. 3 ed. São Paulo: Perspectiva, 1992).

MILLS, C. Biopolitics. London and New York: Routledge, 2018.

\section{Kherlley Caxias Batista Barbosa}

Professor Associado do Curso de Filosofia da Universidade Federal do Tocantins (UFT). Licenciado em Filosofia pela Pontifícia Universidade Católica de Goiás, Bacharel e Mestre em Teologia pela Pontificia Facoltà San Bonaventura (Roma). Doutor em Filosofia pela Universidade do Vale do Rio dos Sinos - UNISINOS/RS. 